\title{
Advanced High-Strength Steels by Quenching and Partitioning
}

\author{
Ilchat Sabirov 1,*, María J. Santofimia ${ }^{2}$ and Roumen H. Petrov 2,3 (D) \\ 1 IMDEA Materials Institute, 28906 Getafe, Madrid, Spain \\ 2 Department of Materials Science and Engineering, Technical University of Delft, 2628 CD Delft, \\ The Netherlands; M.J.SantofimiaNavarro@tudelft.nl (M.J.S.); Roumen.Petrov@UGent.be (R.H.P.) \\ 3 Department of Electromechanical, Systems and Metal Engineering, Ghent University, B-9052 Ghent, Belgium \\ * Correspondence: ilchat.sabirov@imdea.org
}

Citation: Sabirov, I.; Santofimia, M.J.; Petrov, R.H. Advanced High-Strength Steels by Quenching and Partitioning. Metals 2021, 11, 1419. https:// doi.org/10.3390/met11091419

Received: 26 August 2021

Accepted: 27 August 2021

Published: 8 September 2021

Publisher's Note: MDPI stays neutral with regard to jurisdictional claims in published maps and institutional affiliations.

Copyright: (c) 2021 by the authors. Licensee MDPI, Basel, Switzerland. This article is an open access article distributed under the terms and conditions of the Creative Commons Attribution (CC BY) license (https:// creativecommons.org/licenses/by/ $4.0 /)$.

\section{Introduction and Scope}

Quenched and partitioned (Q\&P) steels are recently developed materials with carefully selected chemical compositions and multiphase microstructures resulting from precisely controlled heating and cooling processes. The concept of quenching and partitioning process was first proposed in 2003 by Speer et al. [1]. In 2009, they appeared on a production line of Baosteel and were successfully commercialised in 2012 in other steel companies [2]. The key treatment parameters include annealing temperature, quenching temperature, partitioning temperature, and time. The careful control of these parameters, along with the steel chemistry, leads to a variety of multiphase microstructures showing a wide range of properties.

The principles of microstructural design in Q\&P steels for improvement of their mechanical strength with no (or very low) reduction of tensile ductility have been understood to a satisfactory level by now. However, the steel performance for a specific industrial application is not governed just by its mechanical strength and ductility under uniaxial tension. Enhanced mechanical properties need to be combined with improved performance properties (such as impact resistance, hydrogen embrittlement resistance, etc.), which have been studied to a lesser extent.

This Special Issue presents a collection of research articles addressing the experimental design of industry-relevant $\mathrm{Q} \& \mathrm{P}$-based processes, microstructural design in the $\mathrm{Q} \& \mathrm{P}$ treated steels via appropriate alloying strategy and/or varying the Q\&P treatment parameters, and the Q\&P process-microstructure-properties relationship. Special attention is paid to the stability of retained austenite, which is shown to play a key role in plastic deformation, thus determining the mechanical behaviour of Q\&P-treated steels. The contributions to the Special Issue are summarised below.

\section{Contributions}

Three articles focus on the development of industry-relevant processes consisting of thermo-mechanical rolling, followed by direct quenching and partitioning (DQ\&P). The article by Tang et al. [3] presents a process based on asymmetric hot rolling, followed by a DQ\&P process. It was applied to a Fe-0.2C-1.5Mn-1.3Si-0.2Al (wt.\%) steel, resulting in the formation of an ultrafine-grained microstructure with an excellent combination of the ultimate tensile strength of $\sim 1000 \mathrm{MPa}$ and total elongation of $\sim 35 \%$, and enhanced workhardening behaviour. This was related to higher volume fraction and the higher stability of film-like retained austenite located between martensite laths. A similar process was applied by Wu et al. [4] to a Fe- $0.2 \mathrm{C}-0.68 \mathrm{Si}-1.75 \mathrm{Mn}-0.06 \mathrm{Nb}$ (wt.\%) steel. It was demonstrated that the DQ\&P process refined retained austenite, promoting the TRIP effect and toughness of the grade, in comparison to the alloy without $\mathrm{Q} \& \mathrm{P}$ treatment. The process proposed by Kantanen et al. in [5] was designed for the industrial hot strip production of Fe-0.3C-2.0Mn0.6Si-1.1Al-2.2Cr and Fe-03C-1.9Mn-1.0Si-1.0Cr (wt.\%) steels. The positive effect of DQ\&P on the volume fraction of retained austenite, tensile mechanical behaviour, and impact 
toughness was shown. However, it was concluded that the practical implementation of the DQ\&P process on a hot strip mill may be challenging due to the sensitivity of the mechanical properties to the quenching temperature.

Other articles focus on the microstructural design in steels via Q\&P treatment to improve their mechanical and in-use properties. In the article by Chen et al. [6], the effect of initial microstructure (i.e., before Q\&P treatment) on the microstructure and tensile mechanical properties of a Q\&P-treated Fe-0.19C-1.26Si-2.82Mn-0.92Ni (wt.\%) steel was studied. It was demonstrated that the initial microstructure (ferrite-pearlite, fresh martensite, tempered martensite) affects the prior austenite grain size and Ms temperature, which, in turn, influences the optimum quenching temperature and microstructure developed after Q\&P treatment using the same parameters. Therefore, the same Q\&P-treated alloy with different initial microstructures can show different tensile mechanical behaviour.

Aoued et al. [7] investigated the microstructural evolution during the Q\&P treatment of a model Fe-0.3C-2.5Mn-1.5Si (wt.\%) by using in situ high-energy XRD, atom probe tomography, and image analysis together. Carbide-free bainite was formed within a very short range during the reheating and partitioning step, and its transformation rate and kinetics depended on the quenching temperature. A large part of carbon was trapped in martensite in the form of both $\mathrm{Fe}_{2.6} \mathrm{C}$ iron and segregation on lath boundaries, which was a drag on carbon partitioning from martensite to austenite. It was concluded that the carbon enrichment in austenite is determined by the competition of carbon partitioning from martensite, bainite transformation, and carbon trapping in martensite.

Vercruysse et al. [8] studied the static and dynamic tensile properties of a Q\&Ptreated $\mathrm{Fe}-0-2 \mathrm{C}-1.25 \mathrm{Si}-2.4 \mathrm{Mn}-0.023 \mathrm{Al}$ (wt. $\%$ ) steel in the temperature range from $-40{ }^{\circ} \mathrm{C}$ to $80^{\circ} \mathrm{C}$. The material showed excellent low-temperature tensile properties because of the high thermal stability of retained austenite, which could contribute to the transformationinduced plasticity (TRIP) effect during testing at low temperatures. However, uniform elongation significantly dropped at $80{ }^{\circ} \mathrm{C}$ due to less effective use of the TRIP effect at this temperature. Adiabatic heating during dynamic testing at $-40{ }^{\circ} \mathrm{C}$ also suppressed the TRIP effect, resulting in reduced strength and ductility of the material. The key role of the stability of retained austenite in controlling the mechanical behaviour of Q\&P steels was highlighted.

Arribas et al. [9] explored the effect of high partitioning temperature $\left(550-650{ }^{\circ} \mathrm{C}\right)$ on the microstructure and tensile properties of four low carbon steels with different contents of $\mathrm{Mn}$ and Ni. The partitioning temperatures of $550{ }^{\circ} \mathrm{C}$ and $600{ }^{\circ} \mathrm{C}$ were not effective for stabilising austenite, though austenite reverse transformation at $650^{\circ} \mathrm{C}$ enabled the stabilisation of a high amount of austenite in the final microstructure of grades with high Mn content alloyed by Ni. The improvement of the tensile properties obtained by the application of high-temperature cycles was not significant. The effect of alloying elements and Q\&P parameters on the microstructure and tensile properties of the Q\&P-treated alloys was discussed.

Wang and Huang [10] showed that the hydrogen embrittlement resistance of an ultrahigh-strength Fe-0.3C-1-57Si-2.94Mn Q\&P steel can be improved by applying a higher partitioning temperature $\left(450^{\circ} \mathrm{C}\right)$. Partitioning temperature did not affect the hydrogen trapping properties of the Q\&P-treated steel. The relatively lower stability of retained austenite after partitioning at higher temperature ensured a more sufficient TRIP effect before hydrogen-induced fracture. Additionally, dislocation recovery and carbon depletion at the higher partitioning temperature reduced the flow stress of the martensitic matrix, improving its intrinsic toughness and reducing its hydrogen sensitivity.

\section{Conclusions and Outlook}

The articles published in this Special Issue illustrate potential benefits and challenges for the manufacturing of advanced high-strength steel grades via the Q\&P process. They can be summarised in the following general conclusions: 
- The Q\&P process can be integrated into the manufacturing process directly after hot rolling (DQ\&P process). Various steels showing enhanced mechanical properties have already been produced via this approach. Experimental results indicate that the DQ\&P-processed steels exhibit better properties, compared to their counterparts without DQ\&P treatment. However, the sensitivity of the microstructure and mechanical properties to quenching temperature could be a challenge for the practical implementation of the DQ\&P process on industrial hot strip mills.

- Careful control of chemical composition, initial microstructure, and Q\&P treatment parameters allows effective microstructural design in the Q\&P steels to tune their mechanical and in-use properties. There are numerous microstructural parameters affecting the performance of Q\&P steels. These include volume fraction and size of retained austenite, condition of the tempered martensitic matrix, precipitates, and most importantly, the stability of retained austenite. Control of all these microstructural parameters is the right strategy for the further development of Q\&P steels for industrial applications.

\section{Acknowledgments}

We would like to thank Betty Jin, Section Managing Editor, for her support and active role in the publication of this Special Issue. In particular, we would like to thank all reviewers who have voluntarily contributed to improving the quality of the submitted manuscripts. We are also grateful to all the staff at the Metals Editorial Office, who have productively collaborated on this endeavour. Furthermore, we would like to thank all authors who have contributed their research articles to this issue for their excellent work.

Funding: This research received no external funding.

Conflicts of Interest: The authors declare no conflict of interest.

\section{References}

1. Speer, J.G.; Matlock, D.K.; De Cooman, B.C.; Schroth, J.G. Carbon partitioning into austenite after martensite transformation. Acta Mater. 2003, 51, 2611. [CrossRef]

2. Wang, L.; Speer, J.G. Quenching and Partitioning Steel Heat Treatment. Metallogr. Microstruct. Anal. 2013, 2, 268. [CrossRef]

3. Tang, Z.; Huang, J.; Lu, X.; Ding, H.; Zhang, D.; Misra, D. Superior Mechanical Properties and Work-Hardening Ability of Ultrafine-Grained Quenched and Partitioned Steels Processed by a Novel Approach Involving Asymmetric Hot Rolling. Metals 2018, 8, 872. [CrossRef]

4. Kantanen, P.; Somani, M.; Kaijalainen, A.; Haiko, O.; Porter, D.; Kömi, J. Microstructural Characterization and Mechanical Properties of Direct Quenched and Partitioned High-Aluminum and High-Silicon Steels. Metals 2019, 9, 256. [CrossRef]

5. Wu, T.; Wu, R.; Liu, B.; Liang, W.; Ke, D. Enhancing the Mechanical Properties of a Hot Rolled High-Strength Steel Produced by Ultra-Fast Cooling and Q\&P Process. Metals 2019, 9, 958. [CrossRef]

6. Chen, B.; Liang, J.; Kang, T.; Cao, R.; Li, C.; Liang, J.; Li, F.; Zhao, Z.; Tang, D. A Study of the Optimum Quenching Temperature of Steels with Various Hot Rolling Microstructures after Cold Rolling, Quenching and Partitioning Treatment. Metals 2018, 8 , 579. [CrossRef]

7. Aoued, S.; Danoix, F.; Allain, S.; Gaudez, S.; Geandier, G.; Hell, J.; Soler, M.; Gouné, M. Microstructure Evolution and Competitive Reactions during Quenching and Partitioning of a Model Fe-C-Mn-Si Alloy. Metals 2020, 10, 137. [CrossRef]

8. Vercruysse, F.; Celada-Casero, C.; Linke, B.; Verleysen, P.; Petrov, R. Temperature Dependence of the Static and Dynamic Behaviour in a Quenching and Partitioning Processed Low-Si Steel. Metals 2020, 10, 509. [CrossRef]

9. Arribas, M.; Gutiérrez, T.; Del Molino, E.; Arlazarov, A.; De Diego-Calderón, I.; Martin, D.; De Caro, D.; Ayenampudi, S.; Santofimia, M. Austenite Reverse Transformation in a Q\&P Route of Mn and Ni Added Steels. Metals 2020, 10, 862. [CrossRef]

10. Wang, Z.; Huang, M. Improving Hydrogen Embrittlement Resistance of Hot-Stamped 1500 MPa Steel Parts That Have Undergone a Q\&P Treatment by the Design of Retained Austenite and Martensite Matrix. Metals 2020, 10, 1585. [CrossRef] 